\title{
O Uso da Linguagem de Programação no Ensino de Matemática: Uma Experiência em Busca de uma Integração Multidisciplinar
}

\author{
Maria Deusa Ferreira da Silva \\ Universidade Estadual do Sudoeste da Bahia (UESB) \\ Vitória da Conquista BA, Brasil \\ maria.deusa@uesb.edu.br
}

\author{
Daniel Martins Nunes* \\ Instituto Federal Norte de Minas, Campus Januária \\ Januária, MG, Brasil \\ dmartinsnunes@yahoo.com.br
}

Resumo- Esse artigo traz um recorte da pesquisa de mestrado que visou apresentar uma proposta metodológica de integração entre as disciplinas curriculares do Curso Técnico em Informática Integrado ao Ensino Médio, do IFNMG - Campus Salinas, em específico a Programação de Computadores e a Matemática. Para tanto, fez-se uso do software Octave como ferramenta de apoio, observando que foi possível verificar como a linguagem de programação de computadores auxilia no processo de ensinoaprendizagem de tópicos da Matemática. Os resultados alcançados apontaram para a aprovação do método proposto, visto que os alunos conseguiram realizar as atividades propostas e puderam usar conhecimentos em Matemática e suas habilidades em construção de algoritmos. Além disso, as atividades desenvolvidas propiciaram maior envolvimento com a teoria matemática discutida. Portanto, acreditamos que a proposta promoveu a integração entre as disciplinas, bem como contribuiu para que os alunos observassem a relação intrínseca entre elas.

Palavras-chave: Ensino Integrado, Matemática e Tecnologias Octave.

\section{INTRODUÇÂO}

Este artigo traz os resultados obtidos em uma pesquisa de mestrado, desenvolvida no Programa de Mestrado Profissional em Matemática em Rede Nacional PROFMAT, Universidade Estadual do Sudoeste da Bahia, cujo objetivo foi analisar as contribuições da integração das disciplinas de Matemática e de Programação de Computadores para o processo de ensino-aprendizagem dos alunos do Curso Técnico em Informática Integrado ao Ensino Médio do Instituto Federal do Norte de Minas Gerais - Campus Salinas, Minas Gerais. Nas atividades propostas buscamos valorizar o conhecimento prévio dos alunos sobre programação de computadores para desenvolver um estudo contextualizado com matrizes.
Participaram desta pesquisa duas turmas de $2^{\mathbf{o}}$ ano, totalizando 56 (cinquenta e seis) alunos.

Embora a proposta curricular, do referido curso técnico, objetive uma formação integrada entre as diversas disciplinas, na maioria das vezes essa integração não ocorre. O comum é as disciplinas serem ministradas de forma fragmentada, não havendo, portanto, qualquer diálogo entre elas e o aluno conclui o Ensino Médio Integrado sem essa visão integradora. Por tais fatores, se justifica o trabalho realizado com a proposta de favorecer momentos em que os alunos percebam a relação existente entre a Matemática e a Programação de Computadores com o uso do software GNU Octave (Octave simplesmente).

Conquanto, para a composição deste artigo trazemos as considerações teóricas sobre a inserção das Tecnologias Digitais (TD) no ensino em geral, em particular no ensino e aprendizagem de Matemática; pontuamos alguns aspectos norteadores sobre o que preconiza o currículo integrado nos Institutos Federais de Educação Tecnológica - IF.

Por fim, relatamos como se deu a inserção da linguagem de programação nas aulas de Matemática, ressaltando as estratégias metodológicas desenvolvidas e apresentado parte dos resultados obtidos. Para concluir, fazemos algumas considerações sobre a pesquisa realizada.

\section{II.AS TD NO ENSINO DE MATEMÁTICA}

É fato que vivenciamos atualmente a "invasão" das TD na sociedade, nos espaços escolares e em nossas vidas pessoais e que, muitas vezes, elas nos dominam e nos trazem um "mar de informações", sendo quase impossível viver sem elas. Isso tem se refletido de modo positivo, em algumas situações, uma vez que o conhecimento não fica centralizado nas mãos de poucos, sendo partilhado por 
diversos meios e acessíveis a qualquer um, imprimindo mudanças nas práticas educativas. Para pesquisadores como Kenski [1] e Moran [2] educar em tempos como esse, dominados pelas tecnologias, pela informação de massa e em constante mudança exige dos profissionais da educação um constante repensar sobre suas práticas, não podem ficar inertes e presos a práticas seculares, é preciso atualização e renovação constante para não se tornarem descartáveis.

Por outro lado, em outras situações, a presença das TD tem se mostrado prejudicial, em virtude de os professores demonstrarem incapacidade de saber lidar com elas, uma vez que os alunos as trazem para a sala de aula, utilizandoas durante o trabalho docente e, consequentemente, prejudicando seu rendimento escolar, conforme pontuam Gabriel [3] e Moran [2]. Desse modo, a maioria dos professores se sente perdido sobre como utilizar essas tecnologias, como acompanhar o ritmo acelerado com que as mudanças ocorrem e como utilizá-las em suas práticas educativas, para o bem da aprendizagem de seus alunos. Em tempo, os autores ressaltam que o acesso fácil que os alunos têm às TD não implica em fatores que contribuam para a sua aprendizagem.

Diante dessa dualidade de concepções muitos professores ficam em dúvida quanto a sua utilização ou não em suas aulas. Dessa forma, alguns buscam respostas para as suas dúvidas ou se acomodam diante dessa "invasão" tecnológica, excluindo-as de suas práticas pedagógicas. Para os que se preocupam com essa temática é comum surgir questionamentos do tipo: Por que devemos inserir as TD no processo de ensino-aprendizagem de Matemática? Quais implicações surgirão ao adequar essas ferramentas às aulas de Matemática? Como utilizá-las no processo de ensino-aprendizagem de modo a provocar o aluno a participar ativamente?

Em relação à primeira pergunta ela surge a partir do posicionamento de professores que ainda não conseguem ver as TD como ferramentas que possam contribuir para a mudança de suas práxis e/ou contribuir com a aprendizagem dos alunos. Na verdade, vêm as TD com desconfiança, uma vez que, baseados em sua longa experiência, se acomodam com a metodologia tradicional de ensino, têm medo de arriscar, se colocando numa zona de conforto, conforme tratado por Borba e Penteado [4]. Assim, acreditam ser essa a única metodologia capaz de superar as dificuldades dos seus alunos.

Todavia, mesmo os mais resistentes, admitem que vivemos rodeados pelas TD e não devemos estigmatizá-las, nem estar alheios às contribuições delas ao processo de ensino e aprendizagem. Agir, assim, só os distanciará dos alunos, tornando-os dispensáveis por eles, como tem ocorrido em muitas escolas brasileiras. Portanto, ignorar, rejeitar ou proibir o uso das TD na sala de aula não é a melhor estratégia a ser adotada pelos professores. É preciso que saibam intervir, no sentido de tratar a informação acessada pelos alunos de modo construtivo, promovendo discussões em sala de aula com uso delas, sabendo coordenar o momento de usá-las dos que não são úteis. É, sem dúvida, um grande desafio

Ainda, sobre as questões anteriormente postas, pontuamos as nossas observações a partir dos trabalhos realizados por Borba [5], Borba e Penteado [4], Brasil [6], Carneiro e Passos [8], Gabriel [3], Maltempi [8], Moran [2], e, Teodoro e Lopes [9]. De um modo geral, esses pesquisadores apontam para a inserção das TD no ensino de Matemática, às vezes especificando o seu uso para determinados conteúdos ou, até mesmo, sobre a necessidade de atualização dos nossos conhecimentos, enquanto professores que buscam mudar a sua prática e se desenvolver sempre.

Desse modo, em Brasil [6] e Borba [4] ao propormos alguma atividade almejando o uso de TD no ensino de Matemática, devemos atentar para o que é denominado "pensar ou investigar matematicamente" que consiste em provocar no aluno a ação de pesquisar, perpassando pelas fases de experimentação, análise de hipótese, testar as suas conjecturas e validar seus resultados. Ou seja, a todo o momento devemos considerar o aluno no centro do processo de aprendizagem

Corroborando com essa visão, vemos que isso é possível pelo fato de que alguns softwares voltados para o ensino de Matemática. Tais ferramentas, além de conciliar os conhecimentos matemáticos que precisamos, permitem 
a interação do usuário com os objetos por ele construídos. Sobre essas características, Borba [4] reitera que elas auxiliam os alunos a se apropriarem do conhecimento matemática de modo mais dinâmico. Basta lembrarmos, por exemplo, que no estudo dos conteúdos envolvendo principalmente Geometria e Funções os alunos necessitam, às vezes, de um modelo visual para a compreensão das especificidades destes temas, os quais, com o uso de softwares, poderiam ser bem melhor trabalhados, facilitando o aprendizado.

Em contrapartida, Borba e Penteado [5] alertam para o fato de que, ao manipular as TD, podem ocorrer resultados que não foram previstos devido à nossa falta de familiaridade com o software ou com o conteúdo matemático abordado. Também podem ocorrer situações em que, ao planejar a aula, o professor se esqueça de verificar todas as possibilidades de solução e resultados e que, no momento da experimentação, isso seja observado. Contudo, os autores reiteram que, essas situações ocorridas durante o processo não devem ser vistas, pelo professor, como fatores que o influencie a não inserir as TD na sua prática em sala de aula. Pelo contrário, a ocorrência dessas situações deve se tornar momentos importantes para a discussão dos resultados em sala de aula com os alunos, mostrando-lhes que eles também contribuíram durante a ação provocada.

Em tempo, é necessário que ambos (professor e aluno) experimentem situações em que seja possível o uso de TD de forma prudente, em que o desenvolvimento cognitivo seja o objetivo do professor, tendo o cuidado de não tornar a sua ação um momento de mera descontração Borba, Penteado [4], mas de reflexão e aprendizado. Além dessas considerações, em Maltempi [8], encontramos outra ideia que contribuiu para responder aos nossos questionamentos, se aproximando do que realizamos em nossa pesquisa. $\mathrm{O}$ autor aborda sobre a ligação entre a teoria Construcionista presente no uso da programação de computadores aliado ao ensino de Matemática. Segundo ele, essa ligação, possibilita a criação de ambientes de aprendizagem. $\mathrm{O}$ autor ainda reitera que essa ideia: é tanto uma teoria de aprendizagem quanto uma estratégia para a educação, que compartilha a ideia construtivista de que o desenvolvimento cognitivo é um processo ativo de construção e reconstrução das estruturas mentais, no qual o conhecimento não pode ser simplesmente transmitido do professor para o aluno [8].

Dessa forma, embasados por essas discussões, bem como nas atividades propostas em nossa pesquisa, buscamos criar um ambiente de aprendizagem no qual nossos alunos fossem participantes ativos do processo e, ainda, intervíssemos o mínimo possível na ação proposta. Assim, com base nas ideias apresentadas, esperamos que a nossa contribuição para a discussão sobre o tema faça sentido para aqueles que buscam uma solução para a utilização das TD no processo de ensino e aprendizagem. É preciso lembrar que a utilização das TD, nessa perspectiva, demanda construção de competências do professor e dos alunos envolvidos, portanto, é um processo contínuo e que pode demandar paciência e tempo.

A seguir apresentaremos algumas considerações sobre o currículo integrado e sua importância para a pesquisa.

\section{O CURRÍCULO INTEGRADO}

A discussão sobre o currículo integrado se fez importante em função do objetivo central de nossa pesquisa, a qual visou, a partir da realização de atividades, verificar como ocorre a integração entre Matemática e Programação de Computadores. Dessa forma, se fez necessário refletirmos sobre os significados dessa integração curricular, ou, mais especificamente, da necessidade de constituição de um currículo integrado nas escolas, em especial nos IF. Portanto, a despeito do currículo integrado, segundo Ramos [10] é posto da seguinte forma:

O currículo integrado organiza o conhecimento e desenvolve o processo de ensino-aprendizagem de forma que os conceitos sejam apreendidos como sistema de relações de uma totalidade concreta que se pretende explicar/compreender [10]

Desse modo, a concepção de Currículo Integrado preconiza a interação entre as disciplinas da área técnica e as disciplinas da área propedêutica. Embora pareça fácil essa integração, na prática tem sido uma tarefa difícil. Tal 
dificuldade, acreditamos, estar associado ao fato de os professores não compreenderem a dimensão políticapedagógica da proposta e se mostrarem relutantes em trabalhar em conjunto com outras áreas do conhecimento. Contudo, estabelecer um currículo integrado pode trazer benefícios à aprendizagem dos alunos ao mostrar-lhes que "Nenhuma teoria é final, assim como nenhuma prática é definitiva, e não há teoria e prática desvinculadas" [10].

Por vezes, essa integração pode ser entendida pelos professores como um processo de interdisciplinaridade. Entretanto, tal ação não pode ser observada apenas dessa forma, mas como um modo de criar condições de ressignificar a aprendizagem dos alunos, aproveitando os conhecimentos que eles possuem para aprendizagem de novos conceitos, Ramos [10]. Ou seja, as disciplinas não devem se tornar ilhas dentro do currículo integrado devem trazer significados e conduzir os alunos a perceberem que elas são indissociáveis, Brasil [6].

A adoção de um currículo integrado parece ser realmente uma alternativa para o ensino, em especial o técnico, uma vez que, como observado por Ramos [10], um dos papéis da escola é, também, a preparação de seus estudantes para a sua totalidade, "resgatando a centralidade do ser humano no cumprimento das finalidades do ensino médio e da educação profissional! [10] ou, posto de outra forma, da formação cidadã desses alunos.

Além disso, devemos considerar que as posturas dos envolvidos no processo educacional tenham que mudar para se atingir os preceitos traçados pelo currículo integrado. Ou seja, em todo o processo de ensinar o professor deve desenvolver uma postura de orientador, instigando os seus alunos a constante ação de pesquisar e não limitando a aprendizagem deles, como têm ocorrido, muitas vezes, durante o desenvolvimento de aulas tradicionais, Brosseau [11].

Desenvolver essas habilidades pode ser complexo para muitos professores, no entanto, com o uso das TD, essa tarefa pode se tornar mais fácil. Isso porque utilizando softwares matemáticos podemos realizar a integração que tanto buscamos, possibilitando aos nossos alunos o desenvolvimento de habilidades que lhes sirvam de aprendizado para o enfrentamento de situações reais, com as quais se depararão no futuro, Gabriel [3].

É um processo árduo, pois vencer o nosso comodismo, enquanto professores ao reproduzir informações encontradas nos livros didáticos ou na internet, parece ser mais tentador do que repensar a nossa prática e propor mudanças, conforme aponta Moran [2].

Diante dessa discussão e de acordo com o objetivo da nossa proposta, o uso das TD, por meio de um software, como o octave, que se utiliza de uma linguagem de programação, surgiu como uma possibilidade real de permitir essa integração curricular, possibilitando aos alunos refletirem sobre as informações fornecidas pelo software, seus conhecimentos sobre linguagem de programação e confrontá-las com os conceitos matemáticos envolvidos. Dessa forma, para uma maior imersão no que tratou a pesquisa, trazemos a seguir algumas considerações a respeito da construção de algoritmos nas aulas de Matemática.

\section{CONSTRUÇÃO DE ALGORITMOS NO PROCESSO DE ENSINO-PRENDIZAGEM}

Começamos conceituando o que é um algoritmo, segundo Farrer et. tal [12], o algoritmo é “a descrição de um conjunto de comandos que, se "obedecidos", resultam em uma sucessão finita de "ações" [12]. Esses comandos são criados com auxílio de um software, que tem como base alguma linguagem de programação, tais como Pascal, $\mathrm{C} / \mathrm{C}++$ ou Java. Assim, os usuários desse tipo de software devem conhecer alguma dessas linguagem de programação para construírem diversos algoritmos, que servirão para uma finalidade específica.

Complementando essa definição, Manzano [13] cita que o algoritmo ainda pode ser definido como:

[...] um processo de cálculo matemático ou de resolução de um grupo de problemas semelhantes. Pode-se dizer também que são regras formais para obtenção de um resultado ou da solução de um problema, englobando fórmulas de expressões aritméticas [13].

Portanto, o que torna mais precisa a ideia da relação da Matemática com o desenvolvimento de algoritmos é a capacidade de propor e modelar situações problemas, 
empregando um software que usa alguma linguagem de programação. O professor de Matemática, ao analisar um pouco mais o seu trabalho, desenvolvido em sala de aula, poderá perceber diversas situações problemas que podem ser utilizadas para construir algoritmos. Exemplificando, temos a situação representada na Figura 1, a qual relaciona o contexto de equações do $2^{\circ}$ grau a um processo algorítmico:

Figura 1 - Organograma para resolver uma equação do $2^{\circ}$ grau

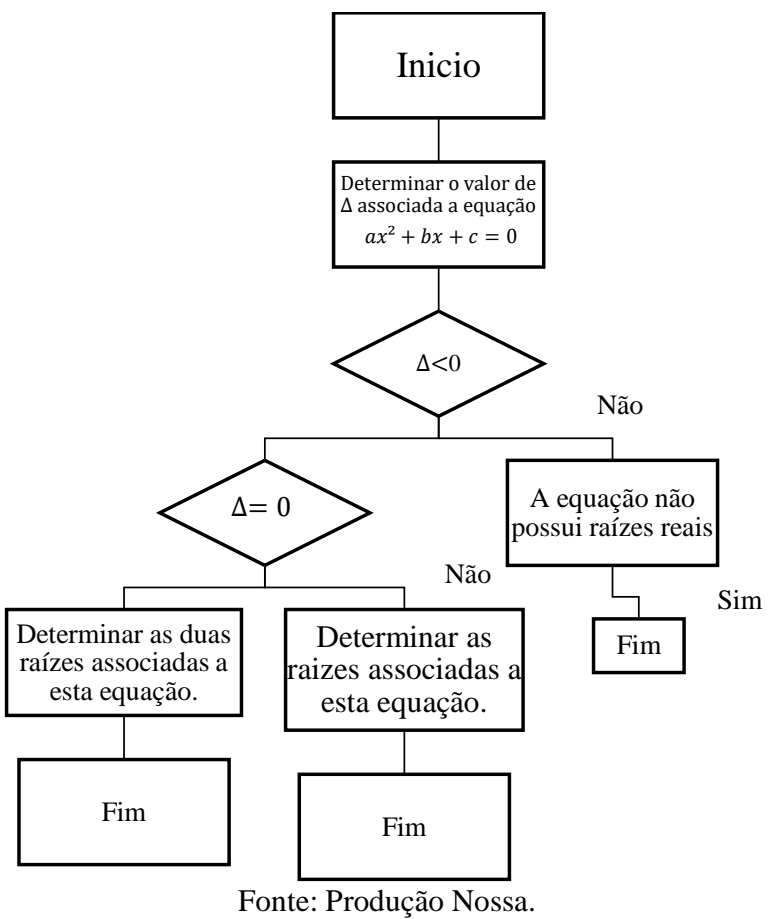

Dessa forma, não é nenhuma novidade se algum livro sobre programação de computadores trazer atividades que exijam a criação de algoritmos, envolvendo algum conteúdo da disciplina de Matemática. Embora não utilize, necessariamente, uma fórmula matemática, ao longo do seu desenvolvimento esse conteúdo será utilizado.

Nesse sentido, Valente [15], destaca que:

Quando o aprendiz programa o computador, este pode ser visto como uma ferramenta para resolver problemas. O programa produzido utiliza conceitos, estratégias e um estilo de resolução de problemas. Nesse sentido, a realização de um programa exige que $o$ aprendiz processe informação, transforme-a em conhecimento que de certa maneira, é explicitado no programa [15].

Desse modo, o momento de construção de algoritmos pode se tornar importante para o professor de Matemática pelo fato de oportunizar situações em que possa intervir e contribuir para que o aluno observe os seus erros e, aos poucos, adquira mais autonomia para resolver problemas. Logo, o processo de aprendizagem durante a construção de algoritmos, é baseado na prerrogativa do erro como virtude para a ocorrência do aprendizado, tão bem ressaltados por Maltempi [8] e Luckesi [14], "pois atua como um motor que desequilibra e leva o aprendiz a procurar conceitos e estratégias para melhorar o que já conhece" [8].

O professor deve ter em mente que nesse processo deverá intervir, não apenas informando ao aluno a linguagem de programação utilizada para a construção do algoritmo, mas também compreender como ele está concatenando os seus conhecimentos, durante o processo, para melhor orientá-lo, conforme recomenda Valente [15]. Além dessas considerações, durante a fase de construção de algoritmos podemos observar o estabelecimento do ciclo composto pelas fases descrição-execução-reflexãodepuração, que podem auxiliar o trabalho do professor, conforme apresentado por Maltempi [8]. Esse ciclo pode ser expresso pela figura 2 , a seguir:

\section{Figura 2 - Ciclo de aprendizagem (Descrição-Execução- Reflexão-Depuração)}

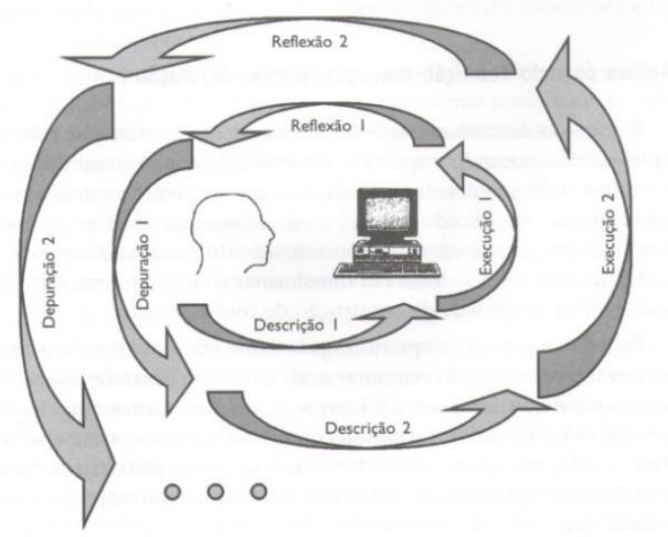

Fonte: Maltempi [8]

Ainda para Maltempi [8] essas etapas em ciclo têm as seguintes características:

- Descrição: etapa em que o aluno cria sequência de comandos usando alguma linguagem de programação no computador, a fim de representar a solução do problema. 
- Execução: é a etapa realizada pelo computador, e tem por finalidade compilar (verificar) o algoritmo construído e apresentar o resultado na tela.

- Reflexão: após a etapa anterior, o resultado exibido na tela poderá fornecer ao aluno alguma resposta ao seu planejamento construído, verificando se o mesmo está correto, podendo também demonstrar falhas na sua construção.

- Depuração: essa etapa decorre da anterior quando for preciso rever a solução do programa construído. $\mathrm{Na}$ ocorrência de erros, o aluno vai tentar novamente solucionar o seu problema voltando ao início do ciclo e refazendo, assim, a atividade.

Todas essas etapas são importantes para o aprendizado do aluno. Contudo, é na etapa da depuração que realmente pode ocorrer maiores contribuições, ainda, essa etapa é que provoca no aluno a busca por novas informações para solucionar o problema e:

\begin{abstract}
esse processo ocorre via tentativa e erros, no qual o aprendiz parte dos aspectos já conhecidos da solução do problema e segue construindo suas próprias teorias. As teorias que não forem adequadas vão sendo descartadas ou alteradas até se tornarem cada vez mais estáveis [9].
\end{abstract}

Logo, o estabelecimento desse ciclo foi o que esperamos dos alunos, envolvidos na pesquisa, ao desenvolverem os seus algoritmos nas atividades propostas.

\section{ASPECTOS METODOLÓGICOS}

Faz-se necessário, antes de adentrarmos à abordagem desse estudo, definir o que vem a ser pesquisa. Dessa forma, Bicudo [16], define que:

Pesquisar configura-se como buscar compreensões e interpretações significativas do ponto de vista da interrogação formulada. Configura-se também, como buscar explicações cada vez mais convincentes e claras sobre a pergunta feita [16].

Ou seja, por meio da relação estabelecida entre o objeto de estudo e o pesquisador poderão ser realizadas descobertas científicas, gerando, dessa forma, novos conhecimentos. Do ponto de vista procedimental, essa pesquisa se enquadra como uma pesquisa-intervenção, uma vez que observamos os aspectos significativos referentes à aprendizagem dos alunos, por meio do desenvolvimento de uma proposta que visou à integração dos conhecimentos técnicos do uso da linguagem de programação aliados aos conhecimentos matemáticos. Entretanto, ao observarmos o surgimento de tais aspectos, estamos também inseridos no processo e, por este fato, podíamos a todo instante, intervir na dinâmica do processo educacional, sugerindo mudanças na dinâmica das aulas.

Além disso, a pesquisa não visou quantificar dados, mas captar a percepção dos envolvidos no processo, o que nos levou a uma pesquisa de natureza qualitativa. Quanto a essa abordagem, Borba e Araújo [17] relatam que:

[...] pesquisas realizadas segundo uma abordagem qualitativa nos fornecem informações mais descritivas, que primam pelo significado dado às ações [17].

Daí a necessidade de nos atermos ao comportamento dos elementos envolvidos, conjuntamente com o objeto de estudo da pesquisa, e não a números, os quais não ajudariam a responder o questionamento inicial.

Ainda, como ressaltado por Borba e Araújo [17], a pesquisa qualitativa deve primar pela característica de um viés descritivo da realidade que o pesquisador está em contato, bem como interessar-se pelo processo e não pelos resultados e produtos, sendo o significado de vital importância para a pesquisa. A fim de alcançar tais pontos, o pesquisador deve procurar analisar os dados coletados de modo indutivo.

Portanto, diante das argumentações traçadas nesse tópico e dos objetivos propostos, ressaltamos novamente que esta pesquisa se configurou como uma pesquisaintervenção, de natureza qualitativa.

\section{V.1 Dos procedimentos para a realização da pesquisa e produção dos dados}

Como ressaltamos anteriormente, a pesquisa foi desenvolvida no IFNMG - Campus Salinas, Minas Gerais, com os alunos do $2^{\circ}$ ano do Curso Técnico em Informática Integrado ao Ensino Médio.

Para obtenção dos resultados, os quais descreveremos a seguir, desenvolvemos duas atividades em momentos distintos, sendo que a primeira delas teve por finalidade 
familiarizar os alunos com alguns comandos do software Octave e abordar conceitos envolvendo operações matriciais, as quais foram utilizadas no segundo momento.

No segundo momento os alunos foram direcionados a resolverem as atividades, tomando como base os conhecimentos prévios sobre programação de computadores e a análise de situações-problema que, nesse caso, optamos por abordar as transformações geométricas no plano.

Por fim, com vistas a analisar as percepções dos alunos aplicamos um questionário. Com a aplicação desse questionário visamos dispor de mais um meio pelo qual os alunos participantes pudessem avaliar as atividades propostas, pontuando os benefícios para a sua aprendizagem ou, até mesmo, trazerem informações críticas sobre a necessidade de melhorar as atividades propostas.

Quanto à estrutura do questionário, utilizamos questões abertas. Essa escolha se justifica pelo fato de que "as questões abertas, [...], prestam-se melhor a coletar informações qualitativas" [9], e por estar de acordo com a natureza desta pesquisa. E para análise e discussão dos resultados seguimos as orientações de Fiorentini e Lorezanto [18] e Ludke e André [19], tomando como base os objetivos propostos e a pergunta diretriz dessa pesquisa para compor as categorias que apresentamos a seguir.

Salientamos que, para a análise e a discussão das respostas dos alunos obtidas durante o desenvolvimento das oficinas, tivemos como orientação os princípios do processo avaliativo, apontados por D'Ambrósio [21] e Hoffmann [21]. Para D’Ambrósio [21], quando solicitamos ao aluno sintetizar aquilo que foi aprendido em sala de aula, estamos the possibilitando aprimorar os seus conhecimentos matemáticos. Nessa mesma perspectiva, Hoffman [21] aponta que o professor deve depositar confiança no aluno para que ele construa suas verdades a partir da sua experimentação, e valorizar o esforço do aluno ao manifestar as suas ideias e interesses.

\section{V.2 Breve análise e discussão dos resultados obtidos}

Como já dito, para a realização da pesquisa foram desenvolvidas duas oficinas. A oficina I, teve o propósito familiarizar os alunos com o manuseio do octave e, ao mesmo tempo, revisar conceitos de matrizes e, a oficia II, inserir o uso do software Octave para trabalhar o conteúdo matrizes. Desse modo, os dados apresentados nesse artigo referem-se ao desenvolvimento da oficina II, uma vez que nesta se efetivou a integração entre utilização da linguagem de programação e conteúdos matemáticos.

\section{V.3 Análise e discussão da oficina II}

Nesta discussão, apresentaremos os resultados da segunda oficina. Com o desenvolvimento dessa oficina, observamos como essa relação pode ser construída, para benefício do processo de ensino-aprendizagem. Para a análise e discussão dos resultados optamos por dividi-los em categorias, as quis apresentamos na sequência.

\section{- $\quad$ Categoria I: Construção do modelo matemático}

Para a construção do modelo matemático e, posteriormente do algoritmo, os alunos observaram inicialmente as atividades contidas no material impresso. Assim, de acordo com a nossa análise, os alunos conseguiram perceber as relações existentes entre matrizes e transformações geométricas, como revelado pela Figura 6: Figura 3: Modelo criado pelos alunos para a Reflexão
em torno do eixo y

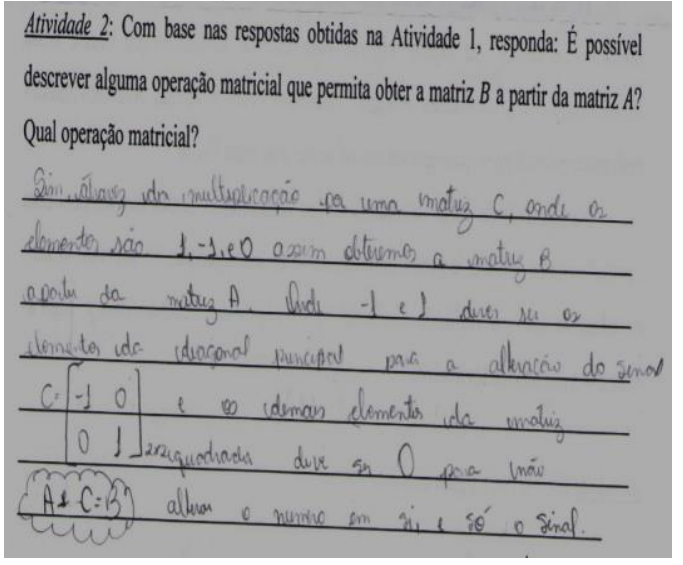

Fonte: Produção Nossa

Essa e outras situações ilustram a compreensão dos alunos sobre a operação realizada, a qual corresponde a uma transformação linear e, em seguida, com base em suas 
observações, identificaram qual operação matricial estava envolvida.

Ainda, é oportuno destacar que, como professores, devemos promover ações pedagógicas que leve o aluno a refletir sobre o que está realizando e evitar, conforme apontado por D'Ambrósio [20], apenas memorizar conteúdos que seriam oportunos para um dado momento de sua escolarização. Além disso, percebemos que a realização da oficina anterior trouxe benefícios para essa, uma vez que os alunos relacionaram o conteúdo anteriormente estudado e apresentaram suas respostas sem muita dificuldade.

\section{- $\quad$ Categoria II: Construção do algoritmo}

Durante a fase de construção dos algoritmos, alguns grupos de alunos se destacaram pela criatividade e pelo envolvimento na resolução dos problemas. Um dos grupos, que aqui denominaremos de Grupo A, construiu o algoritmo que apresentamos na Figura 8:

Figura 4: Algoritmo construído no software Octave para a Translação de objetos

$\begin{array}{ll}1 & \text { function }[B]=\text { translacao }(\mathrm{A}, \mathrm{z}, \mathrm{x}) \\ 2 & \mathrm{y}=\mathrm{A}(:, 1)+\mathrm{z} ; \\ 3 & \mathrm{~W}=\mathrm{A}(:, 2)+\mathrm{x} ; \\ 4 & \mathrm{~B}(:, 1)=\mathrm{y} ; \\ 5 & \mathrm{~B}(:, 2)=\mathrm{W} ; \\ 6 & \mathrm{e}=\mathrm{A}(:, 1) ; \\ 7 & \mathrm{t}=\mathrm{A}(:, 2) ; \\ 8 & \text { plot }(\mathrm{e}, \mathrm{t}, \mathrm{Y}, \mathrm{w}) ; \\ 9 & \text { endfunction }\end{array}$

Fonte: Produção Nossa

Para a construção do algoritmo, o Grupo A usou o comando $A(:, 1)$, em que 1 representa a ordem da coluna selecionada da matriz $A$. Salientamos que em nenhum momento de nossa explicação introdutória tínhamos feito referência a esse comando, uma vez que nos preocupamos em exemplificar apenas a estrutura inicial do algoritmo e alertar para que observassem o material disponibilizado, no qual são descritos tal comando e outras sintaxes.

Em comparação, com a nossa proposta de solução para a atividade, percebemos que a construção feita pelos alunos se mostrou mais simples do que a nossa, contudo atenderam aos requisitos propostos na atividade. Convém salientar, que em nenhum dos algoritmos construídos os alunos apresentaram uma solução utilizando os mesmos comandos que prevíamos para solução das atividades.

Dessa forma, compreendemos que não podemos rotular a solução de um problema por um único modo, seja ele envolvendo a Matemática ou a Programação de Computadores. Pode ser comum nos depararmos com raciocínios diferentes para um mesmo problema, sendo necessário observarmos com atenção cada uma dessas soluções.

Devido ao êxito na atividade, os demais alunos buscaram o auxílio do Grupo A, o que resultou num processo de construção e interação bastante produtivo entre os grupos. Também houve troca de conhecimentos, à medida que os alunos discutiam os seus problemas, uma vez que os temas eram diferentes e demandavam atenção para interpretar a proposta. Para Moran [2], essa interação é benéfica para o processo educacional, visto que, para o autor, o conhecimento se consolida pela dualidade entre teoria e prática e da interação social, bem como quando eles conseguem aplicar os seus conhecimentos em situações que compreendem.

Daí a importância de termos construído as atividades de modo a prevalecer a interação entre os pares de grupos, o que poderia não ter ocorrido, caso optássemos por trabalhar apenas o individualismo. Embora a maioria dos grupos tenham buscado resolver os seus problemas recorrendo a ajuda do Grupo A, outros também foram além, ao acrescentarem elementos que tornaram únicos os seus algoritmos. Por exemplo, destacamos o Grupo B, que, durante a construção do algoritmo que lhe foi proposto, conforme figura -7, utilizou comandos "input" e "printf", permitindo a interação do usuário com o computador, demonstrando criatividade e originalidade na execução da atividade. Analisamos isso como algo preponderante as ideias construcionistas, conforme Maltempi[8]. 
Figura-7: Algoritmo construído pelos alunos para a mudança de

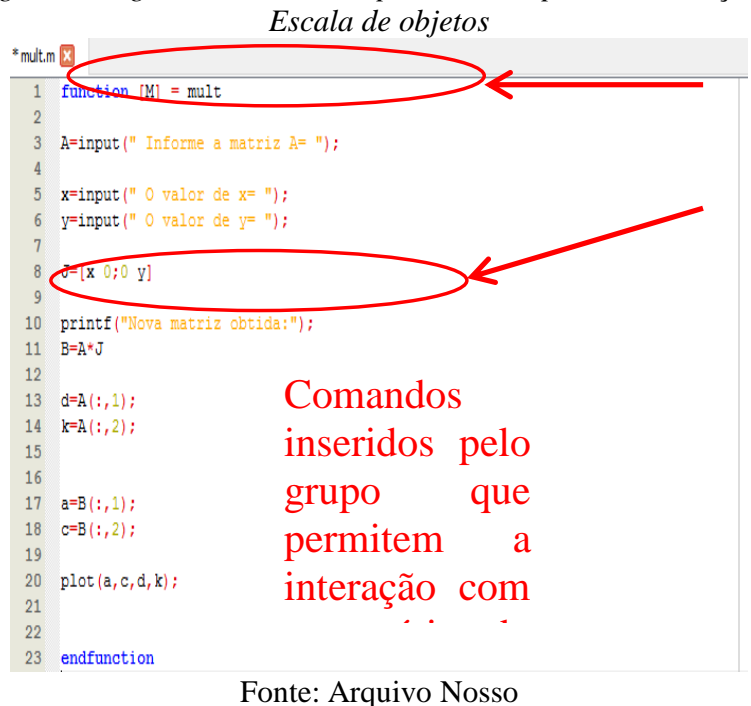

Já o Grupo C, apresentou uma solução que nos levou a uma discussão interessante: durante a construção do modelo matemático, que descrevia a operação de reflexão em torno do eixo $y$, o grupo justificou que a solução foi determinada pela divisão entre matrizes, conforme figura8. Contudo, a operação de divisão entre matrizes não é definida, erraram apenas nesse ponto, uma vez que os resultados encontrados estão corretos, com a relação à matriz que realiza a transformação geométrica e com o algoritmo por eles construído. Entretanto, a justificativa que torna correta a solução do Grupo C deve-se ao fato de que, no software Octave, "para resolver um sistema linear do tipo $A x=B$ em Matlab/Octave, usa-se a barra invertida ( $)$, fazendo $A \backslash B$. ." [22]. Dessa forma, os alunos não realizaram a divisão entre as duas matrizes e, sim, apresentaram a resolução de sistemas lineares.

Figura -8: Solução apresentada pelos alunos envolvendo "divisão" de matrizes

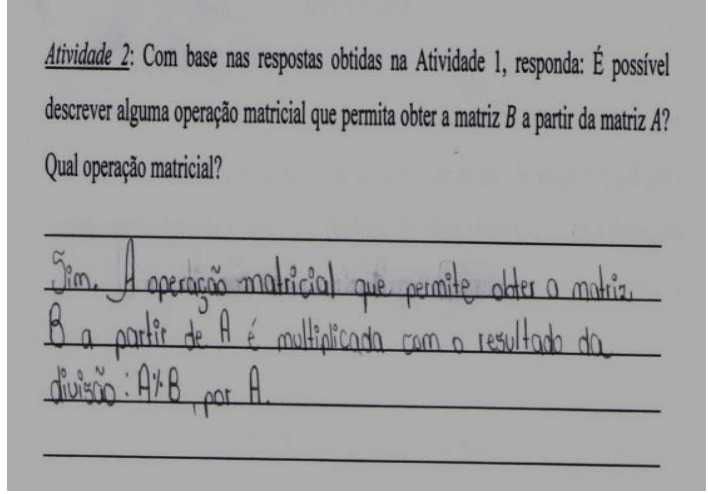

Fonte: Arquivo Nosso
Por fim, é interessante observar que os alunos conseguiram realizar as conexões entre o que aprenderam em suas aulas de Programação de Computadores e as atividades propostas por nós, visto que buscamos também utilizar seus conhecimentos prévios sobre o assunto. Assim, concluímos que as propostas desenvolvidas trouxeram resultados positivos, ao usarmos os conhecimentos dos alunos sobre linguagens de programação de computadores no trabalho com os conceitos de Matemática abordados. Além disso, respondemos às nossas indagações inicialmente formuladas quanto ao emprego de conhecimentos da área técnica da Informática na abordagem de conceitos matemáticos.

\section{BREVES RESULTADOS}

\section{VI.1 Percepção dos alunos a partir do Questionário}

A aplicação desse questionário foi importante para a nossa pesquisa, visto que durante o desenvolvimento das atividades não pudemos perceber todas as dúvidas e inquietações dos alunos, o que foi possível captar melhor por meio do questionário. Dentre os fatores que pontuamos, a partir da visão dos alunos, os benefícios da proposta, a integração entre os conteúdos e as dificuldades enfrentadas.

Dessa forma, de modo geral, para os alunos, as TD auxiliam no processo de ensino e aprendizagem da Matemática e não o contrário, como revelam os comentários a seguir:

- Com o software o entendimento sobre o assunto se torna mais fácil, por isso achei superinteressante. (Aluno 14);

- Interessante, devido através do software ocorrer uma fixação e deixa mais claro a compreensão com os desenhos no gráfico. (Aluno 16);

- Diferenciado das demais formas tradicionais, porem interessante onde o aluno interage mais pois se utiliza software e outros meios para que possa compreender o assunto. (Aluno 48);

- Foi legal, pois saímos um pouco da rotina sem deixar a matéria de lado, e fora que as aulas ficaram mais animadas. (Aluno 32) 
- Achei bem legal, acredito que essa instituição deveria trabalhar assim, não só trabalhando a tradicional aula somente dentro da sala de aula. (Aluno 34)

Dessa forma, com o desenvolvimento das oficinas e, diante, dos relatos dos alunos, entendemos que as nossas ações contribuíram para corroborar com os pontos importantes assinalados por Moran [2] sobre a utilização das TD no ensino, quando este aborda que:

\begin{abstract}
A educação escolar precisa compreender e incorporar mais as novas linguagens, desvendar os seus códigos, dominar as possibilidades de expressão e as possíveis manipulações. É importante educar para usos democráticos, mais progressistas e participativos das tecnologias, que facilitem a evolução dos indivíduos [2]
\end{abstract}

Salientamos que, na pesquisa desenvolvida, buscamos inserir as TD não apenas pelo fato de serem uma tendência para o ensino, mas por entendermos que, de fato, se tornam elementos motivadores da aprendizagem, bem como auxiliam nossa ação pedagógica. Nesse sentido, as respostas dos alunos nos mostram que estamos na direção certa.

Sobre a integração das disciplinas, outro ponto importante, trazemos a visão dos alunos nesse momento. Para eles, a nossa proposta contribuiu para reforçar os seus conhecimentos de programação, conforme deixam ver os relatos a seguir.

- Muito bom, pois fez a gente relembrar da programação em $C$ do ano passado e aprendemos mais sobre matrizes praticando em pc. (Aluno 39)

- Foi muito instrutiva e além disso ainda ajudou a compreender lógica de programação. (Aluno 51);

São relevantes, também, as opiniões dos alunos acerca da importância da contribuição da linguagem de programação para desenvolverem o gosto também pelas aulas de Matemática. De modo geral, os alunos descrevem que a abordagem é interessante, conforme as transcrições a seguir:

- Com essa interação de matemática e uma linguagem de programação desenvolve uma melhor compreensão do aluno e além de ser mais chamativo do que a forma tradicional e nessa metodologia é possível encontrar dificuldades de um aluno de maneira mais eficaz e auxiliálo de uma forma que o faça entender. (Aluno 48)

- Bem alguns alunos têm mais prazer com aulas envolvendo linguagem de programação, talvez com essa relação com a matemática eles possam também gostar e aprender mais a matemática. (Aluno 51)

Portanto, esses relatos também deixam transparecer que a relação entre metodologia e uso do software beneficia o processo de ensino-aprendizagem, uma vez que possibilita ao professor identificar e sanar as suas dúvidas dos alunos. Isso vai ao encontro do que Maltempi [8] assinala sobre a utilização desse software nas aulas de Matemática, para o autor é possível "visualizar e manipular as estratégias e ideias (o metaprocesso) empregados na solução de um problema"[8].

De modo geral, as dificuldades apresentadas relacionavam-se ao desconhecimento da sintaxe dos comandos do software Octave. Como descrevemos aqui, os alunos, de fato, não tiveram problemas em construir a estrutura lógica dos seus algoritmos, requerida para resolver o problema em questão, e erravam porque utilizavam a mesma linguagem de programação que conheciam. Entretanto, essas dificuldades foram pontuais e temporárias, manifestando-se apenas nos primeiros contatos com o software, como já dissemos aqui e os relatos dos alunos confirmam isso:

- A dificuldade é a de iniciante no software, mas com o tempo fica fácil manusear devido a sua interface "familiar" parecida com a do DevC++. (Aluno 13)

- É um pouco difícil para iniciantes, mas consegui concluir as atividades propostas. (Aluno 21)

Apesar dessas dificuldades apresentadas em relação ao manuseio do software, o Octave foi bem aceito pelos estudantes, como os relatos a seguir nos fazem ver:

- Ele possui facilidade quanto a sua plataforma de fácil entendimento, mas quanto a sintaxe de comandos exigiu mais atenção. (Aluno 2)

- Apesar de ter muitos "bugs” o Octave é fácil de trabalhar quando se trata da linguagem. (Aluno 22)

Interessante a observação do Aluno 22, ao relatar a presença de bugs (defeitos) no software Octave. Isso nos alerta para a necessidade de estarmos preparados para 
enfrentar situações em que eles ocorrem e auxiliar os alunos, como nos relembra Borba e Penteado [4] sobre o fato de que as tecnologias não estão isentas de falhas.

Outros relatos, embora destaquem uma boa avaliação do software, chamou-nos a atenção para o fato de que ele possa apresentar fatores de dificuldade para usuários que não possuam conhecimentos básicos sobre programação. Essa preocupação dos alunos também é pertinente. Contudo, podemos observar que a primeira oficina explorada poderá ser aplicada em uma turma de alunos que não possuam conhecimentos de programação de computadores.

Além disso, compreendemos que tudo é uma questão de criatividade e planejamento do professor, uma vez que observamos anteriormente alguns pesquisadores utilizando o software Octave em contextos da Matemática que não demandaram conhecimentos em programação. Assim, vamos ampliando a integração dessas TD no ensino, ao observarmos a sua versatilidade no processo de ensino e aprendizagem da Matemática. Por fim, gostaríamos de salientar que todas essas sugestões serviram para repensar a nossa prática, adequando a nossa proposta para que, a partir desse momento, os nossos erros também possam ser corrigidos.

\section{CONSIDERAÇÕES FINAIS}

Concluímos este trabalho observando que, de acordo com as análises realizadas anteriormente, as nossas expectativas quanto à inserção das TD no ensino e do uso de linguagem de programação como instrumento de integração para as aulas de Matemática, foram correspondidas. Salientamos, ainda, que o desenvolvimento dessas atividades foi importante para que pudéssemos perceber o quanto a prática e a teoria devem estar aliadas no processo de ensino e aprendizagem. Em nada adiantaria elaborar tais propostas se não pudéssemos experimentá-las num ambiente escolar e observar as possibilidades e entraves que podem surgir ao longo da sua aplicação.
Sendo assim, termos observado essas situações foi importante, uma vez que buscamos respostas para as nossas dúvidas. Além disso, como vimos anteriormente, para os alunos foi interessante colocá-los numa situação como sujeitos ativos nesse processo, em que buscaram resolver as situações-problema demonstrando serem capazes de realizar sozinhos as atividades propostas. Ao explorarmos as atividades no Laboratório de Informática, percebemos o quanto que as TD contribuíram para o aprendizado dos alunos.

Ressalte, ainda, que as atividades exploradas contribuíram para que os alunos ficassem atentos às definições e propriedades envolvendo as operações matriciais, haja vista que as mesmas foram discutidas por meio de exemplos e tendo sido, posteriormente, solicitado a descrição de um modelo matemático que as representasse. Isso também foi possível no desenvolvimento da segunda oficina, visto que os alunos deveriam construir programas para exemplificar as transformações planas a partir do modelo matemático construído.

De modo geral, este estudo foi importante para percebemos a necessidade da adoção dessa metodologia em nosso trabalho docente, sem, contudo, resumi-la apenas a essa situação experimental para se tornar uma prática constante, bem como estender a outros conteúdos da Matemática. Todavia, vale assinalar que devemos usá-las sabiamente para não refletir negativamente no processo educacional.

\section{REFERÊNCIAS}

[1] KENSKI, V. Educação e tecnologias: o novo ritmo da informação. $2^{\text {a }}$ ed. Campinas: Papirus, 2007

[2] MORAN, J. M. A educação que desejamos: novos desafios e como chegar lá. Campinas, São Paulo, 2015.

[3] GABRIEL, M. Educ@r: a (r)evolução digital na educação. São Paulo: Saraiva, 2013.

[4] BORBA, M. C; PENTEADO, M.G. Informática e Educação Matemática. $4^{\mathrm{a}}$ ed. Belo Horizonte: Autêntica Editora, 2010. 104 p. 
[5] BORBA, M. C. Softwares e Internet na sala de aula de Matemática. In: Encontro Nacional de Educação Matemática, Cultura e Diversidade, 10., 2014, Salvador. Anais... Salvador: SBEM, 2010. P. 1-11.

[6] BRASIL. Ministério da Educação. Secretaria de Educação Básica. Orientações Curriculares para o Ensino Médio: Ciências da natureza, matemática e suas tecnologias - Vol. 2. Brasília: 2006.135 p.

[7] CARNEIRO, R. F; PASSOS, C. L B. A utilização das Tecnologias da Informação e Comunicação nas aulas de Matemática: Limites e Possibilidades. Revista Eletrônica de Educação, v. 8, n. 2, p. 101-119, 2014.

[8] MALTEMPI, M. V. Construcionismo: pano de fundo para pesquisas em informática aplicada à Educação Matemática. In: BICUDO, Maria Aparecida Viggiani.

[9] TEODORO, J V; LOPES, J M. Evolução e perspectivas da tecnologia em sala de aula e na formação docente. Revista Educação e Fronteiras On-Line, Dourados/MS, v.3, n.8, p.91-104, maio/ago. 2013

[10] RAMOS, M. Possibilidades e desafios na organização do currículo integrado. In: FRIGOTTO, G; CiavatTA, M; RAMOS, M (Orgs.). Ensino Médio Integrado: Concepção e contradições. $2^{\mathrm{a}}$ ed. São Paulo: Cortez, 2010. P. $106-127$.

[11] BROSSEAU, G. Introdução ao estudo das situações didáticas: onteúdos e métodos de ensino. Tradução de Camila Bogéa. São Paulo: Ática, 2008. 128 p.

[12] FARRER, Harry; BECKER, Christiano Gonçalves; FARIA, Eduardo Chaves; MATOS, Helton Fábio de; SANTOS, Marcos Augusto dos; MAIA, Miriam Lourenço. Programação Estruturada de Computadores: Algoritmos Estruturados. $3^{\mathrm{a}}$ ed. Rio de Janeiro: Editora LTC, 1999.

[13] MANZANO, José Augusto N. G. Estudo Dirigido: ALGORITMOS. São Paulo: Editora Érica, 2000.

[14] LUCKESI, C C. Avaliação da Aprendizagem Escolar. 19a ed. São Paulo: Cortez, 2008.
[15] VALENTE, J. A. Análise dos diferentes tipos de softwares usados na Educação. In: BRASIL. Ministério da Educação. Secretaria de Educação a Distância. Programa Nacional de Informática na Educação. O computador na sociedade do conhecimento. Brasília: MEC, 1999. P. 7186.

[16] BICUDO, M. A V. Pesquisa em Educação Matemática. Pro-Posições, Campinas, v. 4, no 1, p. 18 23, março, 1993.

[17] BORBA, M. C; ARAÚJO, J. L (Orgs.). Pesquisa Qualitativa em Educação Matemática. $4^{\mathrm{a}}$ ed. Belo Horizonte: Autêntica Editora, 2012. 144 p.

[18] FIORENTINI, D; LORENZATO, S. Investigação em educação matemática - Aspectos teóricos e metodológicos. $3^{\text {a }}$ ed. Campinas: Autores Associados, 2009. 217 p.

[19] LUDKE, M; ANDRÉ, M. E. D. A. Pesquisa em Educação: abordagens Qualitativas. $2^{\text {a }}$ ed. Rio de Janeiro: E.P.U., 2013. 112 p.

[20] D’AMBRÓSIO, U. Educação Matemática: Da teoria à prática. $23^{\mathrm{a}}$ ed. São Paulo: Papirus, 2012.

[21] HOFFMANN, J. M. L. Avaliação: mito e desafio. Uma perspectiva construtivista. $11^{\mathrm{a}}$ ed. Porto Alegre, Educação \& Realidade, 1993.

[22] NETO, Fernando Gonçalves de Almeida; NASCIMENTO, Vítor Heloiz. Apostila Introdutória de Matlab/Octave. São Paulo, 2011. Disponível em: http://disciplinas.stoa.usp.br/pluginfile.php/256601/mod_r esource/content/1/apostila_matlab_octave.pdf. Acesso em: 01 de jun. de 2016 